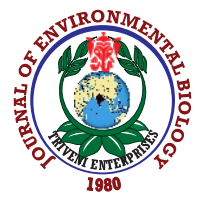

\title{
Main problems of the sustainable development of the South Caucasus and processes of transformation of landscapes (ecosystems) biodiversity
}

\author{
N. Elizbarashvili ${ }^{1 *}$, N. Sulkhanishvili ${ }^{1}$, B. Kalandadze ${ }^{2}$, G. Meladze ${ }^{1,5}$, T. Gordeziani $^{3}$, T. Gorgodze ${ }^{4}$, T. Donadze ${ }^{3}$, M. Meladze $^{5}$, R. \\ Elizbarashvili ${ }^{6}$ and D. Sidamonidze \\ 'Department of Regional Geography and Landscape Planning, Tbilisi State University, 0179, Tbilisi, Georgia \\ 2Department of Soil Geography, Tbilisi State University, 0179, Tbilisi, Georgia \\ ${ }^{3}$ Department of Cartography and Geomorphology, Tbilisi State University, 0179, Tbilisi, Georgia \\ ${ }^{4}$ Department of Topography, Ministry of Defense, 0112, Tbilisi, Georgia \\ ${ }^{5}$ Department of Hydrometeorology, Georgian State Technical University, 0160, Tbilisi, Georgia \\ ${ }^{6}$ Department of Human Geography, Tbilisi State University, 0179, Tbilisi, Georgia \\ *Corresponding Author Email : nelizbarashvili@yahoo.com
}

\begin{abstract}
Aim: This study is dedicated to the problems and indicators of sustainable development of the South Caucasus, assessing the contemporary and promising state of the landscape (ecosystems) of the same region.

Methodology: The indicators of sustainable development are the indices used to evaluate and show the levels and trends of national, regional and global development. The analysis of such indicators is used to forecast the peculiarities of political, economic, social and ecological development of the geographical environment. The main goals of the environmental impact assessment are: 1. Protection of human health, natural environment, as well as cultural and material values, and 2. Consideration of the ecological, social and economic interests of the state and public.
\end{abstract}

Results: Determinant of environment condition, the structure and functioning of the landscape are stipulated by as natural, so anthropogenic factors. The basic criterion of the determination of current condition of natural environment, stipulated structural, functional, ethologic or physiognomic features, can be considered by following groups:1. Practically invariable, 2. Insignificantly modified, 3. Middling changed, 4. Strongly modified and 5. Practically transformed landscapes. Thus, the majority of some landscapes of South Caucasus belongs to categories the very strong changed landscapes. On the second place so-so and completely to the middling changed and practically transformed types of landscapes.

Interpretation: The results of the study showed that the following landscapes face problems of sustainable development and biodiversity conservation in the South Caucasus: High - Hydromorphic and sub hydromorphic, Middle Mountainous Cold-moderate and High mountain alpine; Middle -. Plain and foothills

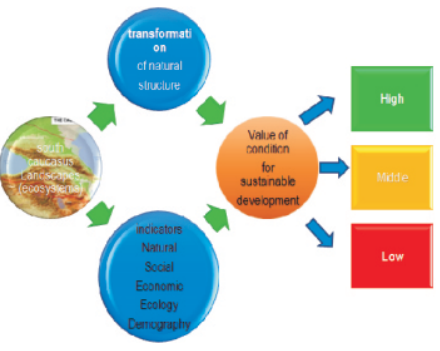
sub-Mediterranean semi-humid, Plain and Foothills Subtropical Arid, Plain thermo-moderate semi humid, Low Mountainous, Subtropical Arid, Low Mountainous Thermo-Moderate Humid, Middle Mountainous Thermo-Moderate Semi-humid; Low - Plain and Foothills-Hill Subtropical Humid, Plain and Hilly Subtropical Semiarid, Low Mountainous Subtropical Semiarid, Middle Mountainous Thermo-Moderate Semiarid.

Key words: Biodiversity, Conditions, Ecosystems, Landscapes, South Caucasus, Sustainability

How to cite : Elizbarashvili, N., N. Sulkhanishvili, B. Kalandadze, G. Meladze, T. Gordeziani, T. Gorgodze, T. Donadze, G. Meladze, M. Meladze, R. Elizbarashvili and D. Sidamonidze: Main problems of the sustainable development of the south Caucasus and processes of transformation of landscapes (ecosystems) biodiversity. J. Environ. Biol., 41, 382-390 (2020). 


\section{Introduction}

Sustainability of any landscape depends upon the structure and functioning of ecosystems (Bargali et al., 1992 a\&b). The three main functions performed by a forest ecosystem are protective, productive and social. Forest structure is both a product and drivers of ecosystem processes and biological diversity. It has become apparent in recent years that changes in forest structure as a result of management or disturbances have undesirable consequences for other components of forest ecosystem ( Bargali, 1995, 2018). The Southern Caucasus (Azerbaijan, Armenia and Georgia) is a mountainous country located at $602 \mathrm{~m}$ above sea level on average in one of the most seismically active zones of the world, on the border between the moderate, subtropical and tropical climatic zones, in the southern part of Holarctic floristic kingdom. The region has all kinds of problems (shortage of land, geodynamic processes, distribution of water resources, development of transport infrastructure, population migration from mountain to lowland, etc.) typical to almost any mountainous region of the world.

With the biodiversity index, the South Caucasus ranks one of the first in the Northern hemisphere with over 6 thousand plant varieties, what, if given in terms of a unit area, gives the region the status of an important Global Biodiversity Center (Biological and Landscape Diversity of Georgia, 2000, Geopolitical Atlas of Caucasus, 2011).

The South Caucasus is also distinguished for high endemism: $1 / 4$ of the plants and animals in the region are endemic. For example, the mammals alone are presented by 152 species, with 30 of them being endemic. There are also many relict species in the region. Southern Caucasus is outstanding with its landscape diversity: although it occupies $0.5 \%$ of the world land, it has $40 \%$ of the types of the world landscapes. It should also be noted that $1 / 10$ of the landscapes in the Southern Caucasus belong to the category of intact or insignificantly transformed landscapes. It is also interesting that homogenous or transboundary landscapes, irrespective of their political appropriation, are characterized by the similar forms of economy and environmental problems. The historical, ethnic, socialeconomic and cultural development and ecological reasoning of the peoples living in the Southern Caucasus show certain similarities (Biological and Landscape Diversity of Georgia,2000).

The countries of the Southern Caucasus, despite their relatively small areas (they occupy only $1 / 3$ of the eco-region) have a central and key geographical position in the Caucasus. High population density with higher concentrations in the intermountain plain, river gorges and mountain basins results in the high anthropogenic impact in these areas (Nikolaishvili, 2011; Elizbarashvili, 2016).
The modern economic and social problems typical to the countries of the South Caucasus influence the sustainable development of the region in general and partially, the sustainable ecological development. On the one hand, the scales of the technogenic impact on the natural environment have diminished, while on the other hand, an interest in "easily accessible" natural resources (forests, water, land, recreational resources, etc.) has increased. Such state of affairs further aggravates the environmental problems.

In the countries of the Southern Caucasus, they feel alarmed at the increased number and scales of the catastrophic geodynamic processes, desertification, reduction of the forest areas, secondary bogging and salination, pollution of water objects, water and wind erosion, degradation of land resources, extinction or reduced number of certain animal species, etc.

Presently, tens of higher plant species, about one hundred mammal species, over one hundred bird species, up to 30 reptile species, etc. are at the brink of extinction. Despite the positive trend in expanding the protected areas, the problem of biodiversity conservation is still one of the severest issues.

The European values are being actively introduced to the countries of the Southern Caucasus. Georgia, Azerbaijan and Armenia have ratified many of the international environmental conventions and have adopted tens of environmental laws; they are establishing the network of the protected areas (including transboundary areas) and jointly realize large-scale regional economic and environmental projects.

The problems of sustainable development of the Southern Caucasus are associated with a number of reasons, with the following ones being important:

Historical particularities of the social-economic development for decades, the countries of the Southern Caucasus were concerned with the goals and objectives of the political and economic development of the former Soviet Union, and as a result, the economics of the countries of this region depended on one another and centralized system. In recent decades, a shift to the market economy takes a successful course gradually promoting the new and extensive economic cooperation. Nevertheless, the influence of the economic specialization of the Soviet era is still strong in the countries of the Southern Caucasus, and it is particularly significant in industry and agriculture. The development of the resort economy is also slow, as it experienced a total fiasco on the background of the geopolitical processes and military oppositions in the last decade of the $20^{\text {th }}$ century (Elizbarashvili et al., 2018).

At the beginning of the $21^{\text {st }}$ century, the specific weight of import increased drastically having a negative impact on the prospects to develop local production and contributing to the unemployment growth. 


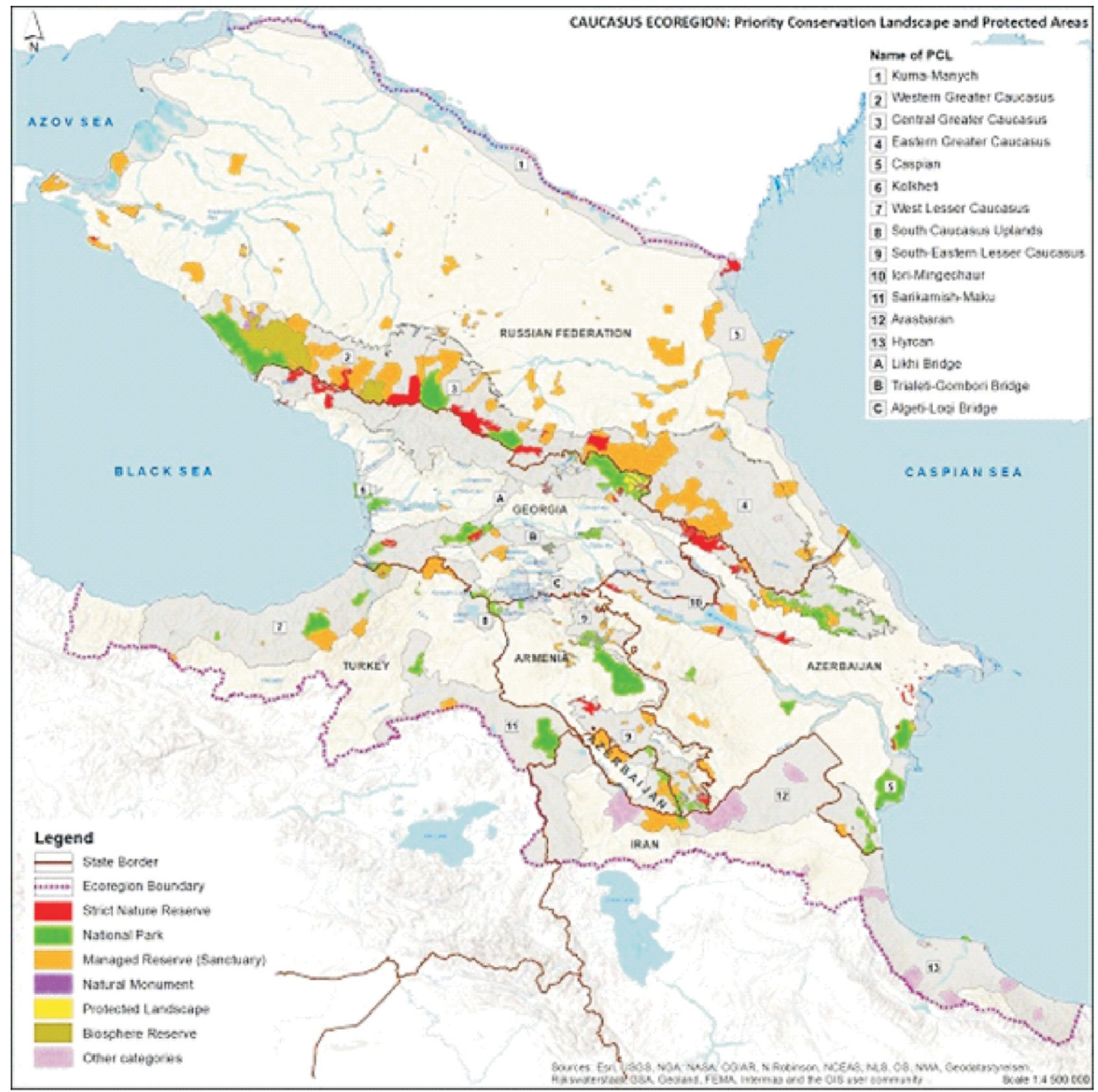

Fig. 1 : Priority Conservation Landscape and Protected Areas (WWF, 2018).

The specialization and geography of the economy had an essentially negative impact. Its production was mainly destined to meet the demands of the Soviet countries and failed to consider the local resources or potential. The disruption of the economic links resulted in the destruction of a number of branches and disqualification of the relevant personnel. The geographical specifics of the distribution of the economy were associated with the intermountain plain (large settled areas) and transport mains in the Southern Caucasus, and as a result, the mountain regions got virtually devastated and the preconditions for the demographic crisis developed there.
Many branches of economy (oil processing, metallurgy, chemical industry, mining, transport, agriculture, etc.) almost failed to consider the ecological demands of the population what became a precondition for the environment degradation in a number of regions. Despite the quite thorough legislation, the environmental problems (e.g. erosion, desertification) have become one of the hampering factors on the way of the local social-economic development.

Modern trends in the development of economy in recent decades, the focus of the social-economic processes on the field 
of service, trade and communications has become evident in the countries of the Southern Caucasus. The aspiration of the countries to have their independent food policy is noteworthy; however, extensive agriculture fails to meet the local demands. Such processes and state of affairs make the local economy even more dependent on the imported goods what leads to the unreasonable expenditure of the currency resources. The majority of the population is employed in agriculture and as a result they have no stable incomes.

Agriculture remains the major specialization of the economy in the countries of the Southern Caucasus. Its development is promoted by favorable and diversified agroclimatic and soil resources. In these countries, it is possible to grow almost all kinds of food and industrial agricultural crops. The production traditions making such products even more attractive are also essential. The raw materials produced in agriculture are the precondition for the food industry to develop what gradually acquires an ecological profile. Despite the high potential, a significant portion of meat, dairy, wheat, vegetable and many other food products are imported to the region. The problems of soil salination, erosion and reduced fertility are still topical in the area. The specialization of agriculture is still chaotic and has not yet made a matter of the state policy.

The summer pastures of the Caucasus and Lesser Caucasus mountains are actively used to develop cattle-breeding what is hardly true with the limited areas of winter pastures. It is known that due to the intense grazing here (the heads of cattle are 4 to 5 times more the admissible level), the problems of desertification and decreased fertility of the pastures are topical in the region.

Extensive agriculture has a negative impact on the natural eco-systems and habitats of a number of wildlife species. The problem is aggravated by the trends of the Climate Change what may become a precondition for the reduced natural productivity of the landscapes in the intermountain plain.

Trends of using natural resources: the energy resources are distributed unevenly in the Southern Caucasus. For instance, Azerbaijan is rich in fuel deposits, while Georgia is rich in hydropower resources. Consequently, the two countries generate the electrical power by employing the resources available to them, while Armenia generates the electrical power mostly by processing the nuclear energy. The principal consumer of the electrical power is the population. However, in recent decades, an increased consumption of the electrical power is seen in industrial and transport fields. Georgia has good prospects to develop hydropower energy. However, the associated environmental problems (including an issue to maintain the Black Sea coastline) and the protest of the local population (in the regions, which are short of lands even so) are still topical.
Trends in transport development The Southern Caucasus must owe its well-developed transport network to its favorable geopolitical location and natural conditions. The Southern Caucasus has already become an essential section of the Great Silk Road, a bridge connecting Europe and Asia and a transport artery between Russia and Western Asia. The Caspian and Black Seas play an extremely important role by connecting the countries of Europe, Near East and Central Asia by means of the rivers and channels.

High specific weight of the mountain regions makes for the high traffic passenger and freight turnover what is the precondition for the aggravation of the ecological state. The problem of atmospheric pollution in the basin-type settlements (Tbilisi, Yerevan, Vanadzor, etc.) is particularly severe. In addition to the traffic flows, the atmospheric pollution is promoted by the poor technical state of vehicles and poor quality of fuel.

The oil and gas transport mains intensely used by a human for more than one century acquire a world geopolitical importance. The oil and gas flows are of both, east-western (Central Asia-Azerbaijan-Georgia-Turkey-Europe) and northsouthern (Russia-Georgia-Armenia-Iran) directions. The transportation of the energy resources via pipelines increases an environmental safety risk what is associated with both, possible technogenic accidents and high seismicity. An increasing freight turnover in the Southern Caucasus is also a precondition for the pollution of the Black and Caspian Seas.

Scales of the forest resources use the forest resources are of a particular importance for the residents of mountain villages. The more the population density in such villages, the more the forest resources they use. The anthropogenic factor has become a reason for the modern deforestation of the largest areas of Javakheti volcanic Plateau and Yerevan Basin, where the forests have been replaced by semi-deserts or mountain steppes.

In the $20^{\text {th }}$ century, the forests of the Southern Caucasus "were left alone", as mostly the inexpensive timber imported from Russia was used in the region. Irregular and rapacious exploitation of the forests was the case in the last decades followed by the activation of the geodynamic processes in many regions. The exploitation of forests in Armenia, Azerbaijan and East Georgia needs special care, as the productive moisture needed for the self-restoration of the forests is particularly low in these regions (particularly, in summer, i.e. in the active vegetation period).

Georgia is rich in forest resources following the country's favorable location and the given kind of the distribution pattern of heat and moisture. Forests regulate air humidity, distribution of precipitations, amount of underground waters, thermal exchange, wind velocity, amount of oxygen, dust and carbonic 
Table 1 : Mine landscape types of South Caucasus and its value of condition for sustainable development

\begin{tabular}{|c|c|c|c|c|c|}
\hline Types of landscapes & $\begin{array}{l}\text { Natural landscape } \\
\text { Diversity, number of } \\
\text { ecosystems species }\end{array}$ & $\begin{array}{l}\% \text { transformation } \\
\text { of naturalstructure }\end{array}$ & $\begin{array}{l}\text { Determined } \\
\text { processes } \\
\text { of landscape }\end{array}$ & $\begin{array}{l}\text { Current } \\
\text { condition }\end{array}$ & $\begin{array}{l}\text { Value of condition } \\
\text { for sustainable } \\
\text { development }\end{array}$ \\
\hline $\begin{array}{l}\text { Plain and Foothills-Hill } \\
\text { Subtropical Humid }\end{array}$ & 10 (high) & 80 & human & 4 & low \\
\hline $\begin{array}{l}\text { Plain and foothills sub- } \\
\text { Mediterranean semi-humid }\end{array}$ & 6 (middle) & 70 & human and natural & 4 & middle \\
\hline $\begin{array}{l}\text { Plain and Hilly } \\
\text { Subtropical Semiarid }\end{array}$ & 2 (low) & 73 & human and natural & 4 & low \\
\hline $\begin{array}{l}\text { Plain and Foothills } \\
\text { Subtropical Arid }\end{array}$ & 1 (low) & 65 & human and natural & 4 & middle \\
\hline $\begin{array}{l}\text { Plain thermo-moderate } \\
\text { semi humid }\end{array}$ & 2 (low) & 55 & human and natural & 4 & middle \\
\hline $\begin{array}{l}\text { Hydromorphic and sub } \\
\text { hydromorphic }\end{array}$ & 2 (low) & 40 & natural & 3 & high \\
\hline $\begin{array}{l}\text { Low Mountainous } \\
\text { Subtropical Semiarid }\end{array}$ & 2 (low) & 85 & human & 5 & low \\
\hline $\begin{array}{l}\text { Low Mountainous } \\
\text { Subtropical Arid }\end{array}$ & 1 (low) & 60 & human and natural & 4 & middle \\
\hline $\begin{array}{l}\text { Low Mountainous } \\
\text { Thermo-Moderate Humid }\end{array}$ & 18 (high) & 65 & human and natural & 4 & middle \\
\hline $\begin{array}{l}\text { Middle Mountainous } \\
\text { Thermo-Moderate Semi-humid }\end{array}$ & 1 (low) & 70 & human and natural & 4 & middle \\
\hline $\begin{array}{l}\text { Middle Mountainous } \\
\text { Thermo-Moderate Semiarid }\end{array}$ & 2 (low) & 85 & human & 5 & low \\
\hline $\begin{array}{l}\text { Middle Mountainous } \\
\text { Cold-moderate }\end{array}$ & 4 (low) & 30 & natural & 3 & high \\
\hline High mountain alpine & 8 (middle) & 10 & natural & 2 & high \\
\hline
\end{tabular}

acid and many other geo-ecological processes. Forests are the best shelters for the wildlife and are thus, have a particular ecological importance.

The standard of life of the local people and high demand of the neighboring countries are directly associated with the types and methods of the forest use what is still one of the topical problems for the sustainable development of the Southern Caucasus.

Trends of the population dynamics: There are about 17 million residents in the Southern Caucasus. The population of Azerbaijan increases relatively rapidly what is hardly true with Georgia or Armenia. Migration and armed conflicts in the region have acquired extremely hazardous scales recently what has become the reason for the depopulation of a number of regions. As various sources suggest, up to 4 million residents have left the Southern Caucasian countries what essentially changed the demographic background and people's age structure in the region. The trend of the population's mass concentration in large cities (Tbilisi, Yerevan) is absolutely evident what aggravates the social-economic situation and hampers the regular development of the peripheries of the countries. As per official data, $1 / 3$ of the total population of the country lives in the capitals of Georgia and Armenia what is 5 or 6 times more the same indicator in the second large cities of the same countries (Batumi and Gyumri).

Large scales of urbanization aggravate the ecological background and social-economic situation. The pollution of atmospheric air, soils and waters and degradation of agricultural plots and biodiversity on the territories of large settled areas and near them are very high.

Geopolitical situation and military conflicts: A significant factor hampering the sustainable development of the Southern Caucasus is both, open and nonmanifest political conflicts having become the reason for a number of permanent military oppositions in recent decades. All three countries of the region are virtually, in the state of war, what has an effect on the economic, social and ecological situation in them. The majority of the conflicts come from the territorial claims what is in fact an unsolved problem for the sustainable development of the region.

Natural risks and disasters: The South Caucasus is located in the active seismic region, what, jointly with the geographical factors, leads to the high natural risks and catastrophic and diversified nature of the natural phenomena. Almost all kinds of catastrophic events and processes known to date are common for the region. The phenomena not fixed in the Southern 
Caucasus include volcanic activities, tropical cyclones, grand floods and freshets. In this respect, the mountains serve a kind of a protective function. However, on the other hand, frequent landslide and mudflow processes, snow and stone avalanches, intense frosts and droughts, hail and tornados are associated with the same mountains. These processes can bring a huge economic damage. Too little is done in the region to prevent or forecast the natural disasters. The network of meteorological and hydrological observations is almost totally devastated thus complicating the monitoring of the environmental processes.

Landslide processes mostly develop in average mountains, in terms of intense humidification and are promoted by earthquakes, underground waters (near the water reservoirs in the first instance), Anthropogenic activities, geology and exposition of the relief. Mudflow currents can cause a great damage or lead to the activation of the secondary processes (formation of landslide bodies). Their intensity depends on the amount of the talus material accumulated in the river gorges as a result of physical weathering and intensity of water mass movement. The mudflow processes are mostly common for the areas with average and low mountains, easily degradable rocks, degraded forests and intense rains. Floods are mostly common in the regions with low-mountain and plain reliefs with a high proportion of atmospheric precipitations (snow particularly) in the alimentation of their rivers. The floods occurring at the beginning of spring or summer sometimes last for some months. The flood intensity increases when heavy rains coincide with snowmelt. The floods can be regulated only by means of water reservoirs or coast-protecting structures. Snow avalanches are one of the significant natural calamities in the high-mountain areas of the Southern Caucasus (Elizbarashvili et al., 2018). The main areas where snow avalanches are commonly formed are highly inclined slopes without any forest at 2 to 4 thousand $\mathrm{m}$ altitude. Avalanches are also frequent at other altitudes bringing a great material damage to the population and transport communication. The intensity and frequency of earthquakes is associated with the seismic activity of the Caucasian region. They often ended in catastrophes. A number of famous lakes (Ritsa, Amtkeli, Göygöl, etc.) were formed as a result of blocking-up the area with the mountain rocks collapsed as a result of earthquakes. The frequency and intensity of the earthquakes has drastically increased for the last half a century. The earthquakes epicenter in the Caucasus is located relatively nearer $(20-30 \mathrm{~km})$ to the Earth surface than in other seismically active regions of the world causing particularly great material damage. Drought is a natural disaster common in the eastern and southern regions of the Caucasia occurring in the arid and semiarid climatic zones. The topicality of droughts increases following the Climate Change. The negative outcomes of intense droughts associated with the desertification and depopulation are clearly seen in many regions of Armenia and Azerbaijan. Drought prevention is associated with the rational and efficient use of water resources. This aspect will gain more importance in the future (as the climatic forecasts suggest).

As the trends of the economic development in the countries of the South Caucasus are not based on the single principles of nature use and do not consider a single methodology of territorial planning, they may become a significant barrier on the way of both, the sustainable development and the regional cooperation. Landscape planning, as an approved and important instrument in Europe for environmentally oriented territorial planning, is capable of harmonizing the processes associated with the nature use in the countries of the Southern Caucasus.

\section{Methodology of assessment of indicators of Sustainable development and landscape condition: The indicators of sustainable development are the indices used to evaluate and show the levels and trends of national, regional and global development. The analysis of such indicators is used to forecast the peculiarities of political, economic, social and ecological development of the geographical environment.}

The main environmental indicators of sustainable development are considered to be: Level of degradation of land, water, atmospheric air, plants and animals, eco-systems and landscapes; Scales of using the natural resources; Scales of ecological policy and ecology-oriented territorial planning and realization; Outcomes of realization of the national environmental legislation and international conventions; The indicators of sustainable development can be classified based on various approaches (systemic, complex, target) and country's strategic policy (view). The classification units may be associated with:

The level and state of development (characterizing the processes, efficiency, safety, freedom of action, responsibility and outcomes of the public activities); The planning and management perspectives (characterizing the opportunity to respond and forecast) (Antipov, Semenov, Elizbarashvili,2009).

The national indicators of sustainable development are desirable to be based on the international experience, methodology and specifics. Such an approach is the precondition for the successful (efficient) comparative analysis. The difference may be seen in such indicators, which characterize the local ethnic culture (values of views), ethnic and historical values, legal traditions, specifics of individual branches of economy, etc.

The environmental problems may also be viewed depending on the individual components of the geographical layer (lithosphere, atmosphere, hydrosphere, biosphere, pedosphere). Such an approach is efficient when the natural components are evaluated by considering their resource potential. For instance, the lithosphere may be assessed according to the relief forms or site altitude and opportunities to develop ore deposits or various branches of economy. 
On April 10, 2018, a meeting with the aim to develop and plan the regional dialogue and cooperation between the scientists and practitioners regarding natural calamities and climate change in the Caucasus Region was held. The meeting identified the priorities of the actions, which will diminish the population's vulnerability to the above-mentioned problems and support the regional cooperation to overcome the challenges of adaptation. Among them are the improvement of the efficiency of the educational disciplines associated with the natural calamities (landslide, mudflow, avalanche, earthquake, etc.) and implementation of the international experience in this field at higher educational establishments.

\section{The main goals of the environmental impact assessment are:}

Protection of human health, natural environment, as well as cultural and material values, and Consideration of the ecological, social and economic interests of the state and public.

Environmental impact assessment envisages the procedure of studying the planned activity and responses of the environmental elements. It is used to make direct and indirect assessments of the impacts of the activity on the environmental components, landscape and eco-systems, natural and cultural heritage and social and economic development.

In assessing the impacts on the landscape, the geographical peculiarities of the landscapes, scales of natural and anthropogenic impacts, sustainability features and transformation parameters are taken into account, in particular: Type, sub-type and genera of the landscape; Geographical location: geographical units (river basin, orographic units), settled areas, altitude of the site; Relief: dominant slope gradients, forms and types of the relief; Geomorphology: dominant type of a geomorphological process (what is it associated with), geology (what does it support), nature and intensity of the geodynamic processes; Climate: general features, average seasonal temperatures, average annual amounts and seasonal distribution of precipitations, dryness index, comfort/discomfort indices of the climatic characteristics; Soil: type and strength, vertical and mechanical structure; Vegetation: type, strength and frequency, degree of transformation; Type of economic use; Degree of stability; Degree of the landscape transformation.

Up-to-day condition of landscape (Beruchashvili, 1995, Elizbarashvili, 2014, 2016, 2018, Antipov, 2009)) is most important among geo ecologic characteristics. It can be shown by landscape transformation scales and application forms. Among them basic ones are: current structure of landscape, existence of specific geo masses, influence of forms and intensity. According to what kind of influence (natural, social-economic or mixed) is redundant, there is determined character of corresponding process.
Besides, the influence on the landscape can be defined during some time (shortly, periodic, constant), procedural (on components, on complex, on process), scaled (feeble, average, strong) and others. The influence can be considered by modification of source, intensity, periodicity, forms and results. Consequently, the geographic analysis of every kind influence and its results is a labor-consuming scientific-research process which is stipulated as landscape, so variety and scale of influence.

The condition of landscapes is defined by forms and scales of external influence. Character of influence can be considered by ability of self-regeneration of the landscape structure. It is admitted that if the influence touches to the biologic components only, the landscape preserves the self-generation ability. Preservation of the self-regeneration mechanism is impossible if:

The influence coincides or stimulates (increase) the negative natural processes (machines, salinity, ravines, erosion and so on); There is influenced basic landscape creator component or relief and climate; When one ecosystem is exchanged by other, equivalent one.

Any arbitrary influence can bring as negative so positive results. For every nature the extreme Influence causes a destruction of dynamic balance, conversion systemic connections among components, exchange of structure and functioning and so on. In spite of above mentioned, there must be considered in two aspects: first - how well is preserved structuralfunctional features of any landscape after influence and second how well carries out given landscape the social-economic function.

Natural influence and its results we can consider by two forms: direct and indirect. First form is considered in case of extreme hydrothermal conditions (for example a drought, redundant humidity), when directly are exchanged bio-geohorizons and other biomasses (Hydro masses, Herbal masses, soil masses) modify little by little. In the landscape there are passive the relief created processes, active - water cycle, biogeo-cycle, transformation of solar energy and others.

At the analysis of anthropogenic influence there must be supposed that landscape needs self-generation ability for recovery of initial ability. This especially concerns to these landscapes, which have a recourse reproduction and environment recovery functions. Anthropogenic influence differs by form of agriculture, techno genic (industry, building, transport and others), techno-ecological (exploitation of the forests, conflagration and others), recreation activities and others. Anthropogenic influence can be synchronous (various at the same times - in case of many- sided application of the territory) or iterate (when one kind of influence is exchanged from other). 
Synchronous influence basically is represented on the urban like territory, that is, in such landscapes where are performed at the same time agricultural, forest, and water exploitation (Elizbarashvili, 2014, 2015). The influence is iterated in these regions where the seasonal agricultural and recreational loading is great. Such landscapes ere represented basically in mountains. The plane landscapes among mountains of Georgia must be considered as area Synchronous influence where are represented various agricultural and social activities of the population, where is concentrated most part $(80 \%)$ of the society, where are created life environment, industrial, agricultural and transport infrastructure and so on. Influence of agricultural activities is intensive bat they carry periodic character. In spite of periodicity of agricultural technical influence, it is so essential that agrarian landscape structure completely is depended on the purposefulness of such influence. In the agricultural landscapes the agricultural influence is directed for the preservation of desired stable development of agriculture and functioning. As the less corresponds agriculture to the landscape-ecologic conditions, as the less it is stable to the environment factors, the more is the agricultural technical influence and the less profitable is the production.

\section{Results and Discussion}

Determinant of environment condition, the third, mixed influence is characterized for these landscapes, where the anthropogenic influence bears an episodic character. In this case, the structure and functioning of the landscape are stipulated by as natural, so anthropogenic factors. The basic criterion of the determination of current condition of natural environment, stipulated structural, functional, ethologic or physiognomic features, can be considered by following groups (Elizbarashvili, 2013, 2014, 2016;Meladze,2016):

Practically invariable landscapes is transformed less than $5 \%$ of horizontal structure, are preserved specific geo masses, elementary landscapes are changed unimportant, practically there are invariable geo horizons, the landscape condition is completely determined by natural processes.

Insignificantly modified landscapes is transformed 5-20\% of horizontal structure, partially have been changed specific geo masses, vertical structure is changed inconsiderably $(1 / 4)$, the functional parameters are changed, landscapes condition is determined by natural, partially social-economic processes.

Middling changed landscapes is transformed half of horizontal structure, partially or considerably has been changed specific geo masses, geo horizons are changed middling, landscapes condition is determined as by natural, so socialeconomic processes.

Strongly modified landscapes is transformed more than half of horizontal structure, considerably has been changed specific geo masses, considerably has been changed or ecocides vertical structure, has been transformed natural mode, landscapes condition is determined by social-economic (partially natural) processes.

Practically transformed landscapes almost completely has been transformed the horizontal structure (more than $80 \%$ ), essentially has been changed (transformed) specific geo masses, vertical structure has been geocide's, landscape has been changed, there has been transformed all landscapeethologic characteristics, landscapes condition is determined by social-economic processes (Elizbarashvili, 2005).

Thus, the majority of some landscapes of South Caucasus belongs to categories the very strong changed landscapes. On the second place so-so and completely to the middling changed and practically transformed types of landscapes.

The results of the study showed that the following landscapes face problems of sustainable development and biodiversity conservation in the South Caucasus:High Hydromorphic and sub hydromorphic, Middle Mountainous Coldmoderate and High mountain alpine; Middle -. Plain and foothills sub-Mediterranean semi-humid, Plain and Foothills Subtropical Arid, Plain thermo-moderate semi humid, Low Mountainous, Subtropical Arid, Low Mountainous Thermo-Moderate Humid, Middle Mountainous Thermo-Moderate Semi-humid; Low - Plain and Foothills-Hill Subtropical Humid, Plain and Hilly Subtropical Semiarid, Low Mountainous Subtropical Semiarid, Middle Mountainous Thermo-Moderate Semiarid.

Assessment of conditions of landscapes is important link of landscape planning and sustainable development. In it the main role is played natural also by socio-economic factors. Human activities determine a condition of $20 \%$ of landscapes of South Caucasus. At the present stage, an important task is determinations of the current state of the changed landscapes among which the main part is occupied by agriculture modifications.

Conditions of the transformed landscapes in many respects depends on the natural potential which is gradually considered in case of review of specialization separate the direction of agricultural industry, economy and urbanization of South Caucasus. Therefore, at this stage the major scientific a task is creation of methodology of determination not only conditions, but also potential of the transformed landscapes.

In South Caucasus, in the scientific and practical plan, the processes connected with introduction of methodology and experience of sustainable ecology development and landscape planning are actively conducted. Similar processes are connected with owe main aspects: ratification European landscape convention (European Landscape, 2000) in countries 
of South Caucasus. On the basis of the principles of sustainable development and landscape planning, in 4 last years, were created new protected territories (in the southern Georgia - 2 national park, cross-border with Armenia and Turkey, in northern Georgia - the 2 new National parks with cross-border prospect with Russia). In the future is planned to accept participation in scientific practical activities in countries of South Caucasus, connected with creation of ecological corridors, landscapes governance and landscape services.

Similar activity demands more universal methodologies of the landscape and ecological researches focusing on assessment of condition of landscapes.

\section{References}

Antipov, A., Yu Semenov and N. Elizbarashvili: Landscape planning in Transcaucasia. Geogr. Nat.Recour., 30, 286-292 (2009).

Bargali, S.S., S.P. Singh and R.P. Singh: Structure and function of an age series of eucalypt plantations in Central Himalaya, I. Dry matter dynamics. Annals of Botany, 69, 405-411 (1992).

Bargali, S.S., R.P. Singh and S.P. Singh: Structure and function of an age series of eucalypt plantations in Central Himalaya, II. Nutrient dynamics. Annals of Botany, 69, 413-421 (1992).

Bargali, S.S.: Efficiency of nutrient utilization in an age series of Eucalyptus tereticornis plantations in the tarai belt of Central Himalaya. J. Tropic. Forest Sci., 7, 383-390 (1995).

Bargali, S.S.: Forest Ecosystem: Structure and Functioning (Editorial) Curr. Trends For. Res., (2018). DOI: 10.29011/2638-0013. 100020

Beruchashvili, N.: Caucasus: Landscapes, Models, Experiments. Tbilisi, (1995). (In Russian).

Biological and Landscape Diversity of Georgia.: Tbilisi, Published by WWF Georgia Country Office, (2000).

Caucasus Environmental Outlook: UNEP, GRID. Tbilisi (2002).

Geopolitical Atlas of Caucasus.: Tbilisi (2011).

Elizbarashvili, N.: Geo-ecological basics of landscape planning. Tbilisi, (2005). (In Georgian)

Elizbarashvili, N., M. Garford and R. Mamadov: Landscape Planning:
Methodology and Experience in Implementation.- Tbilisi-BonnIrkutsk (2009).

Elizbarashvili N., H. Meessen, G. Meladz, A. Khoetsian and T. Kholer: Sustainable development of Mountain regions and resource management. Tbilisi, (2018). (In Georgian and in English)

Elizbarashvili, N.: Fundamentals of applied Geography. Tbilisi (2016). (In Georgian and in English)

Elizbarashvili, N. and G. Meladze: Main principles and results of landscape planning of new protected area in Central Caucasus (Georgia). 5th Symposyum for research in protected areas. International Conference Volume. Mitterspil, Austria, pp.171-174, (2013).

Elizbarashvili, N., G. Meladze and Z. Seperteladze: Climate change and the Possible Migration of the Population in Georgia. In: Tourism, Environment and Ecology in the Mediterranean Region. Cambridge scholars Publishing, NE6 2XX, UK. Chapter ThirtyOne, p.10(2014)

Elizbarashvili, N., Z. Seperteladze and R. Elizbarashvili: Basic characteristics of stability of mountain landscapes of Georgia. Proceedings of the FG-SHU International Symposium on Geography: Landscapes: Perception, Knowledge, Awareness and Action. In: Geopolitcs, History and International Relations, Addleton Academics Publishers, New York, U.S.A. Vol. 4, 65-73 (2015).

European Landscape Convention. Opening for signature on 20 October 2000, European Treaty Series - No.176, 9 p., Florence. Http://conventions.coe.int

Meladze, D., M. Meladze, N. Elizbarashvili and G. Meladze: Global warming: Changes of agroclimatic zones in humid subtropical, mountainous and high mountainous regions of Georgia. Int. $J$. Curr. Res., 8, 55403-35409 (2016).

Nikolaishvili, D., N. Elizbarashvili and G. Meladze: Evaluation of degree of landscape's anthropogenic transformation (Landscapes of Georgia). The 2nd International Geography Symposium. Mediterranean Environment. Procedia Social and Behavioral Sciences, 19. Antalya (Turkey), pp. 547-555 (2011).

Piloting Landscape Planning in the Countries of the South Caucasus.: Baku, Tbilisi, Yerevan (2009).

World Wildlife Fund [WWF].: An Ecoregional Conservation Plan for the Caucasus. Tbilisi (2018). http://www.wwf.de/fileadmin/fm-wwf /Publikationen 